\title{
Realidade virtual e lógica do espaço
}

\author{
Jaqueline Esther Schiavoni'
}

I - USP

São Paulo (SP), Brasil

Resumo: O objetivo deste artigo é promover uma reflexão acerca da expressão realidade virtual, criada na década de 80 pelo cientista da computação Jaron Lanier, alcançando posteriormente as terminologias realidade aumentada e virtualidade aumentada comumente associadas a ela. A abordagem é feita a partir do instrumental teórico da semiótica francesa, notadamente o quadrado semiótico proposto por Algirdas Julien Greimas. As considerações realizadas propõem o reconhecimento da espacialidade como um dos eixos articuladores possíveis para se pensar a emergência de diferentes tipos de imagens na contemporaneidade e formas de interação exploradas a partir delas.

Palavras-chave: semiótica francesa; realidade virtual; espacialidade.

Abstract: Virtual reality and the logic of space - the goal of this article is to promote a reflection on the expression virtual reality, created in the 80 's by computer scientist Jaron Lanier, reaching later the terms augmented reality and increased virtuality. The approach is based on the theoretical tools of French semiotics, notably the semiotic square proposed by Algirdas Julien Greimas. The considerations put forward propose the recognition of spatiality as one of the possible interacting axes to enable thinking about the emergence of different types of images in contemporaneity and the forms of interaction explored from them.

Keywords: French semiotics; virtual reality; spatiality.

Desde o final do século passado, temos assistido à multiplicação e à diversificação de interfaces computacionais avançadas, chamadas de realidade virtual. Em vista da disseminação de aplicações configuradas a partir de lógicas de interação específicas, outros termos derivados ou relacionados à expressão original também foram se popularizando, a exemplo de realidade aumentada e virtualidade aumentada.

No entanto, a utilização dessas nomenclaturas no mercado - e às vezes até na esfera acadêmica - nem sempre é pacífica: observam-se certos produtos, serviços e experiências 
semelhantes receberem nomes distintos e, de modo inverso, alguns que são essencialmente distintos levarem o mesmo nome. Nosso objetivo com este artigo é tentar abordar o problema, considerando certas lógicas de interação que nos são apresentadas no mundo de hoje a partir do referencial teórico da semiótica francesa, de modo a fornecer um parâmetro conceitual que amplie nossa compreensão acerca de tais iniciativas e possa nos auxiliar quanto ao uso das terminologias.

Nessa empreitada, nos valeremos de modo especial das relações lógicas que estão na base, como as primeiras e mais abstratas instâncias, do percurso gerativo de sentido desenvolvido por Greimas. Cremos que tais relações sejam consideravelmente úteis à discussão na medida em que nos apontam regras de valoração e de inferências que constituem um dos modos mais elementares do ser humano apreender o mundo em que vive.

Visto que as semióticas a serem consideradas se estruturam sobre diferentes regimes de visualidade e a projeção de imagens implica, necessariamente, a projeção de uma determinada configuração espacial, tentaremos dar conta de alguns objetos selecionados para análise - e das classes tipológicas que eles representam - aplicando o sistema de representação do nível fundamental do percurso gerativo, isto é, a lógica do quadrado semiótico, às diferentes espacialidades exploradas, considerando em cada projeto os efeitos de sentido resultantes das escolhas da enunciação nesse âmbito. Começaremos pela análise do que se entende por realidade virtual, alcançando posteriormente as expressões realidade aumentada e virtualidade aumentada.

\section{O eixo dos contrários}

A expressão realidade virtual foi cunhada no final da década de 1980 pelo artista e cientista da computação Jaron Lanier ${ }^{1}$. O conceito levava em consideração experiências e tecnologias que estavam sendo desenvolvidas desde as décadas de 50 e 60 no que diz respeito a sistemas imersivos e interfaces para interação homem-máquina - como o Sensorama, de Morton Heilig, e o Head-mounted Three Dimension Display, de Ivan Sutherland - e tinha por objetivo marcar a busca por um novo estado de coisas cuja essência estava na fusão de dois termos considerados antagônicos: o real e o virtual (2006, p. 4).

Todavia, à luz do instrumental da semiótica francesa, mais exatamente o da lógica que rege o modelo de representação visual da estrutura elementar da significação de um texto ou uma semiótica-objeto qualquer, isto é, o modelo operacional do quadrado semiótico, é possível notar que a expressão de Lanier se ergue sobre uma oposição que pode ser considerada enganosa.

1 Lanier foi um dos pioneiros do Vale do Silício, lugar que concentra as maiores empresas de tecnologia do planeta. Foi responsável por fundar, na década de 80 , a primeira empresa a vender equipamentos que permitiam ao usuário "entrar" em mundos criados no computador, cunhando a expressão realidade virtual para descrever tal experiência (ROSSI, 2010). 


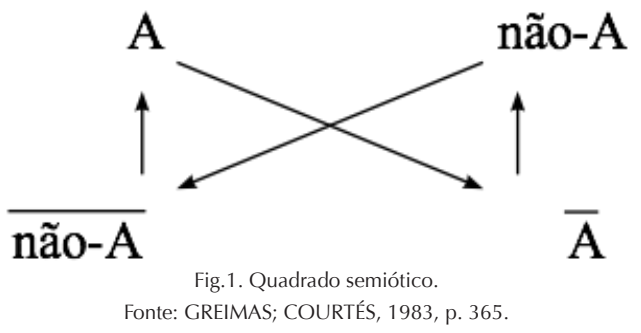

No esboço apresentado, vemos surgir duas operações paralelas de negação por contradição $(\mathrm{A} / \bar{A})$ e (não-A/ não-A $)$ efetuadas sobre determinados termos primitivos, isto é, os contrários que compõem a categoria (A) e (não-A), gerando por contradição dois

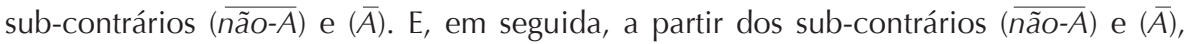
duas operações paralelas de asserção, fazendo aparecer não somente as relações de complementariedade pelo modo como se mostram implicados ( $\overline{\text { não- } A}-» \mathrm{~A})$ e $(\bar{A}-»$ não-A), mas também a relação de contrariedade existente entre os dois termos primitivos $(\mathrm{A})$ e (não-A). O ponto em questão é que,

se, e somente se, essa dupla asserção tem por efeito produzir essas duas implicações paralelas, temos o direito de dizer que os dois termos primitivos pressupostos são os termos de uma só e mesma categoria e que o eixo semântico escolhido é constitutivo de uma categoria semântica. Ao contrário, se $\bar{A}$ não implica não-A, e se $\overline{\text { não-A }}$ implica $A$, os termos primitivos - A e não-A -, com seus contraditórios, se inscrevem em duas categorias semânticas diferentes (GREIMAS; COURTÉS, 1983, p. 365, verbete Quadrado semiótico).

Assim, se para que dois termos mantenham uma relação de contrariedade entre si é preciso, antes de qualquer coisa, que estes pertençam a um mesmo eixo semântico, qual seria então o traço em comum na oposição que Lanier lança entre o real e o virtual? Uma pergunta como essa parece ser demasiadamente pretensiosa. Muitos estudiosos já se lançaram sobre ela e descortinaram, cada um a seu modo, pontos de relevância. Giles Deleuze, Michel Serres, Philippe Quéau, Pierre Lévy são alguns dos que estão nesse círculo, propondo articulações em torno da existência, da presença, da materialidade apenas para citar alguns exemplos.

Visto que os termos em discussão - real e virtual - não são unívocos, isto é, não nos fornecem um único e claro sentido para a análise, mas podem acolher significados vários e serem abordados em diferentes perspectivas - o que muitas vezes torna a oposição enganosa -, como dar conta dos modos de existência e experiência estética que a expressão original almejava alcançar? Nossa proposta é tentar oferecer ao problema um eixo articulador possível, fundado na configuração espacial da imagem. 


\section{O limite entre os espaços}

Quando Jacques Aumont afirma que "olhar uma imagem é entrar em contato, a partir do interior de um espaço real que é o do nosso universo cotidiano, com um espaço de natureza bem diferente, o da superfície da imagem" (2002, p. 136), o que o autor faz é nos colocar diante de uma oposição espacial - interior vs. exterior - que nos acena para a existência de uma zona limítrofe entre os espaços, responsável por delimitar com maior ou menor exatidão onde termina um e começa o outro.

Refletir sobre essa zona limítrofe e, consequentemente, sobre os espaços que ela separa, é fundamental para compreender os efeitos de sentido que entram em jogo com as imagens artificiais, bem como os diversos tipos de interação que elas podem engendrar. Para tanto, nos utilizaremos da noção de quadro desenvolvida pelo próprio Aumont. Conceituando o termo, ele escreve: "o quadro é o que faz com que a imagem não seja infinita, nem indefinida, o que termina a imagem, o que a detém" (2004, p. 112) e, complementando, o autor cita três de suas formas de manifestação mais recorrentes: o quadro-objeto, o quadrolimite e o quadro-janela. Trabalharemos com os dois primeiros conceitos nos parágrafos que seguem. O terceiro, retomaremos mais adiante, na parte final do artigo.

O quadro-objeto diz respeito ao enquadramento físico de uma tela, isto é, a sua moldura. Seu valor está ligado ao entorno que ele fabrica para a obra, lembrando que uma tela bem emoldurada não somente costuma valer mais no mercado como também diz muito sobre o status da própria, de seu artista e de seu possuidor. Assim, está ligado à mobilização da imagem, a seu devir-móvel, a seu devir-objeto e a seu valor de circulação, funcionando como um sinal de que a imagem está à venda e pode ser levada embora. Mas, principalmente, o quadro-objeto funciona como um mediador, um intermediário, integrando a obra ao ambiente em que é disposta - paredes, móveis, tipos de iluminação - ao mesmo tempo em que a separa nitidamente desse ambiente, fazendo a diferenciação dos espaços da representação e da realidade.

Se a obra não tiver qualquer entorno material, restarão ainda os limites físicos do próprio suporte de inscrição. A este tipo, Aumont denominou de quadro-limite. Sua função não é apenas impor limites visuais à imagem, mas também reger a composição da tela. Conforme explica, "o olho é o instrumento que aprecia a justa e harmoniosa relação das massas visuais, seu peso respectivo, seu afastamento do centro ou dos centros. E, nesse jogo, o quadro-limite marca o terreno" (2004, p. 113). É evidente que o autor, nesta fala - ao mencionar aspectos como o equilíbrio e a harmonia da composição - se expressa tendo em vista os códigos da pintura clássica, mas, caso o exemplo se desse em caráter diametralmente oposto, a função do quadro-limite permaneceria inabalada, expondo, apenas, as relações desiguais, desarmoniosas ou descentradas que se inscrevem no quadro. Em todos os casos, porém, deve-se notar que a tela "fala". Investido propriamente de um valor retórico, o quadro-limite funciona como um operador reflexivo, enunciando a si mesmo e à superfície da tela como discurso (AUMONT, 2004, p. 113). 
Reconhecer o valor retórico do quadro-limite significa assinalar que "todos os sentidos possíveis de um quadro estão, a um só tempo, contidos na própria tela, e devem ser lidos a partir de seu lado de fora, o lado de fora mais radical possível, aquele onde nada mais da imagem existe" (AUMONT, 2004, p. 114). Dito de outro modo: "a tela pintada, como enunciado e como significação, se produz e se lê a partir de um espaço que não é o da ficção ${ }^{2}$, mas um espaço discursivo, um fora-de-quadro" (ibidem). Assim, a materialidade da tela-suporte e os limites de sua própria extensão nos colocam frente a dois espaços completamente diferentes: o dentro-do-quadro e o fora-do-quadro. Estes, por sua vez, nos conduzem a instâncias igualmente distintas: a do enunciado e o da enunciação. Para extrair todas as consequências de se considerar o quadro como um operador de espaços é preciso salientar que ele não apenas nos remete à oposição interior vs. exterior, mas, sobretudo, à oposição fechado vs. aberto, pois o quadro como objeto ou como os limites da superfície de uma imagem sempre a circunscrevem, marcando uma zona de existência.

\section{Dos contrários aos contraditórios}

Com o desenvolvimento tecnológico e a crescente capacidade de processamento de dados pelos computadores, a zona limítrofe entre o que está dentro e o que está fora do quadro ou da tela se fragiliza por completo, visto que os novos dispositivos têm sido explorados no sentido de fazer com que o espaço do enunciado e o espaço da enunciação passem a se projetar um no outro e, confundindo-se, façam-nos misturar representação e realidade. Deve-se observar, então, que o foco deixa de estar propriamente nos termos que compõem o eixo dos contrários - fechado vs. aberto - e passa a contemplar os termos que compõem o eixo dos sub-contrários - não-fechado e não-aberto - conforme explicitado na imagem a seguir.

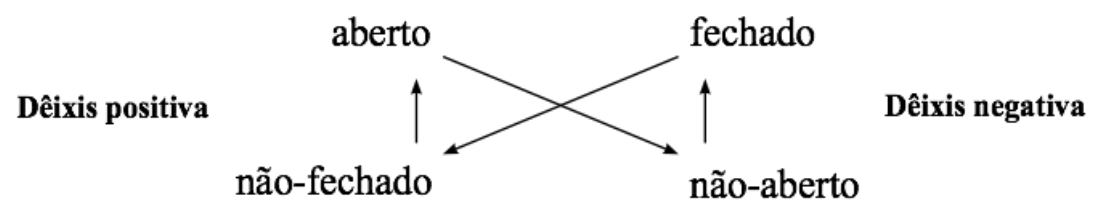

Fig. 2. Espacialidade.

Fonte: Autor.

Mas o que isso tudo significa exatamente e qual é a relação que cada termo mantém com a produção de imagens nos dias de hoje? Neste momento, não nos preocuparemos em utilizar nomenclaturas correntes - muitas delas frágeis e controversas - para designar os quatro tipos de existência esboçados no quadrado semiótico que acabamos de

2 Ao longo do trabalho, manteremos o termo ficção utilizado por Aumont para designar o espaço do enunciado, da representação. 
apresentar. Cremos que seja mais apropriado abordar primeiramente o sentido em torno de cada um deles para, posteriormente, abordar sua relação com alguns dos tipos de imagens que se multiplicam em nossa época.

Sendo assim, valendo-nos das proposições feitas por Henrich Wölfflin acerca das artes clássica e barroca, consideramos como aberto o tipo de representação que "extrapola a si mesmo em todos os sentidos e pretende parecer ilimitado, ainda que subsista uma limitação velada" (WÖLFFLIN, 2015, p. 168). E consideramos como fechado o tipo de representação que "apresenta a imagem como uma realidade limitada em si mesma, que, em todos os pontos, se volta para si mesma" (ibidem). No eixo dos subcontrários, o que se tem é um tipo de existência e/ou experiência intermediária, que comporta uma operação de negação em relação a um determinado termo primitivo - que, neste caso, se denomina aberto ou fechado.

É importante dizer que "nenhum dos quatro termos da categoria é definido de maneira substancial, mas unicamente como pontos de intersecção, como terminais de relações" (GREIMAS; COURTÉS, 1983, p. 367, verbete Quadrado semiótico). Isso é especialmente relevante num trabalho como este, pois, em todos os tipos apresentados sempre deverá haver a presença de um dispositivo que, de alguma maneira, irá cercear a visão - nem que seja nosso próprio olho. Este é o caso do que consideramos, neste trabalho, por espaço aberto. Associamos esse termo do quadrado semiótico ao ambiente do nosso mundo natural, uma vez que este, "extrapolando a si mesmo" ao se desdobrar sobre o infinito, não se encontra de maneira alguma circunscrito. Tal como um "fora de quadro", está associado ao espaço da enunciação e aos efeitos de sentido de realidade. Todavia, recuperando a fala de Wölfflin, subsistirá em toda apreensão visual que fazemos desse mundo natural os "limites velados" do olho humano. Isso se diz não somente porque toda vista que se lança sofrerá sempre as limitações que esse órgão tem, incluindo os recortes que a fisiologia impõe ao homem, mas, para muito além dos limitadores biológicos, é bom lembrar que toda visada também encontrará os limites de sua própria perspectiva histórica:

O pintor, ao contemplar os objetos, sempre o faz a partir de um ponto de vista determinado. Todos nós, pintores ou não, invariavelmente vemos o mundo através de um olhar que, em si, já é ativo. O olhar seleciona. A percepção não apreende o mundo na totalidade, mas somente os aspectos que se ajustam a determinada perspectiva histórica do ver (PEREIRA, s/d, p. 7).

Partindo desse ponto de referência, consideraremos alguns exemplos práticos. O primeiro deles envolve experiências como a que a Samsung propõe com o Gear VR (para melhor compreensão, ver SAMSUNG, 2016). Levando às últimas consequências a apresentação da "imagem como uma realidade limitada em si mesma", o dispositivo utilizado busca encerrar por completo o contato visual do sujeito com o mundo natural obrigando-o, por exemplo, a manter-se imóvel, talvez sentado, a fim de que não tropece 
ou esbarre nos objetos e, por fim, se machuque. Nesse caso, não somente há a presença de uma borda, como, principalmente, a imagem e o tipo de imersão que se propõem dependem dos limites que ela impõe a partir da aparelhagem utilizada. Assim, nesse espaço fechado, a vista do usuário apenas pode fruir as imagens que o dispositivo oferece e estas, tal como um dentro do quadro, ganham um status de enunciado, guardando um efeito de sentido de ficção.

Assim, podemos passar às gradações de sentido que pode haver entre os dois termos primitivos, a saber, os espaços considerados não-fechados e não-abertos. A experiência oferecida pela Microsoft por meio do HoloLens ilustra bem o primeiro caso. Tem-se aí um tipo de produção que nega as condições do espaço fechado, fazendo com que suas imagens características interatuem com as imagens ou objetos do mundo natural, instituindo-o palco ou cenário para o seu desenvolvimento. O esforço está, portanto, em jogar as imagens para fora do quadro. A ideia é que, com a ajuda de dispositivos tecnológicos, as imagens artificiais, criadas por computação gráfica, possam ser ancoradas no ambiente físico do usuário. O diferencial do produto é que ele não atua sob os limites de um espaço fechado, como acontece com o Gear VR. Ou seja, não interrompe por completo a vista do usuário sobre o mundo natural, de modo que este pode não somente visualizar, mas interagir com as imagens de modo livre, deslocando-se no espaço físico em que se encontra.
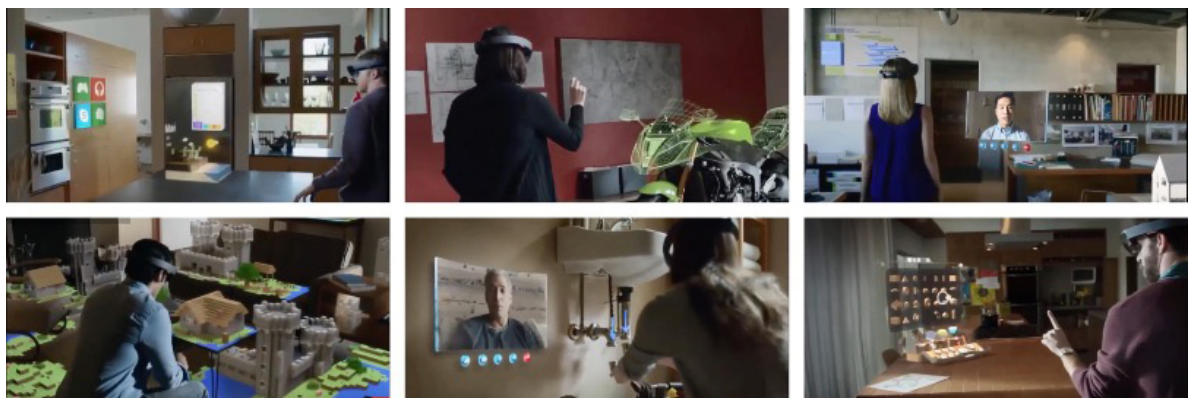

Fig. 3. HoloLens. Imagens do vídeo de divulgação da Microsof HoloLens Transform your world (HOLOLENS, 2015). Em todos os quadros, é possível observar o usuário interagir livremente com imagens artificiais ancoradas em seu espaço físico - cozinha, escritório, sala, banheiro.

No segundo caso, o do espaço não-aberto, o movimento é exatamente inverso. Não se trata mais de enviar as imagens do quadro para o mundo natural, mas de transportar as imagens do mundo natural para o quadro. Veja-se o exemplo de uma instalação feita pela National Geographic. 

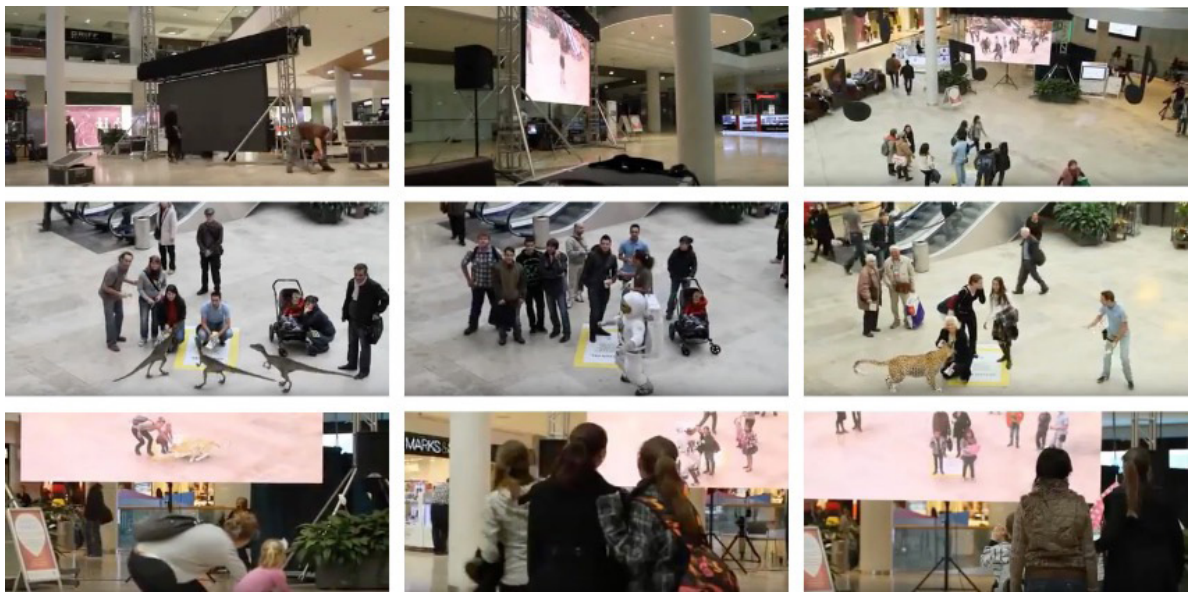

Fig. 4. National Geographic. Imagens do vídeo de divulgação A chance for everyone to step into the world of National Geographic, produzido pela National Geographic (LIVE, 2011). A instalação feita em um shopping center permite que o público, posicionado na área demarcada em amarelo no chão, veja sua figura projetada num telão ao lado de variadas imagens criadas por computação gráfica, com as quais pode simular interação.

Nas imagens selecionadas do vídeo de divulgação da empresa é possível perceber três momentos distintos. O primeiro (na parte superior) nos revela um processo de construção de cena, com a montagem de equipamentos - tela, câmera e a delimitação de uma área para a interação proposta. O segundo (na parte central) nos mostra alguns dos resultados obtidos com a instalação, colocando em evidência a interação do público com as imagens artificiais - dinossauros, leões e astronautas. O terceiro (na parte inferior) expõe o processo por trás da interação, responsável por projetar as pessoas numa grande tela, ao lado de animações diversas. A proposta, absolutamente coerente para um canal de televisão, consistia em colocar as pessoas no centro da tela. Diferentemente da experiência anterior, a imagem está posicionada no quadro e não mais fora dele. É lá que a imagem se realiza e a interação acontece. E é por essa razão que o deslocamento fica cerceado, restrito ao contexto de localização do usuário ou à região para a qual a câmera está direcionada note, nesse sentido, a demarcação em amarelo (na parte central) que aparece no vídeo de divulgação da National Geographic.

A partir dos exemplos apresentados e das considerações que foram feitas sobre eles, é possível perceber que os termos intermediários do quadrado semiótico que propomos se firmam, não pelo simples acréscimo ou sobreposição de um tipo de imagem em outra, mas, pela relação de interdependência ou interação que elas mantêm entre si: no caso das imagens projetadas para fora do quadro, o fato de serem ancoradas no mundo natural terminará por negar as características fechadas de sua gênese artificial, compondo o que se pode chamar de espaço não-fechado. E, de modo inverso, mesmo que as imagens do mundo natural sejam lançadas para dentro do quadro, a pregnância que cada partícula 
exerce sobre o devir de sua representação na tela, em ato, terminará por ver sua gênese e suas características fundamentais de liberdade no espaço negadas ao se confrontar com os limites da cena e o aprisionamento da imagem nos limites da tela, compondo o que se pode chamar de espaço não-aberto. Nos dois casos, tais relações implicam um estado de co-presença: existência ou comparecimento de imagens de diferentes gêneses - natural e artificial - num determinado lugar, a um só tempo. De modo que a ênfase de sentido, caso se trata de um espaço não-fechado ou um espaço não-aberto, decorrerá do lugar em que se pretende que as imagens sejam ancoradas.

Conforme esboçamos no início do artigo, muitas terminologias surgiram a fim de designar tais especificidades de interação de imagens. Por exemplo, Insley define realidade aumentada como "melhoria do mundo real com textos, imagens e objetos virtuais, gerados por computador" (2003 apud KIRNER; SISCOUTTO, 2007, p. 10), o que corresponde ao que definimos como espaço não-fechado. E Kirner e Kirner dizem que a "virtualidade aumentada ocorre quando o mundo virtual é enriquecido com representações de elementos reais pré-capturados em tempo real, que podem ser manipuladas ou interagir no mundo virtual, através de dispositivos multisensoriais" (KIRNER; KIRNER, 2011, p. 16), o que corresponde ao que abordamos como espaço não-aberto. Nosso intuito neste trabalho não é fazer um levantamento das definições existentes, mas mostrar como o instrumental da semiótica nos fornece bases sólidas para pensar sobre tais fenômenos contemporâneos.

Nesse sentido, considerando o caminho proposto no quadrado semiótico - que vai dos contrários aos contraditórios e, portanto, um caminho de negação tanto do real (não-aberto) como do virtual (não-fechado) - talvez o mais correto fosse nomear os sub-contrários como realidade e virtualidade diminuídas em vez de aumentadas. Mas as experiências que os dispositivos tecnológicos oferecem estão à venda. E a propaganda tem seus próprios métodos.

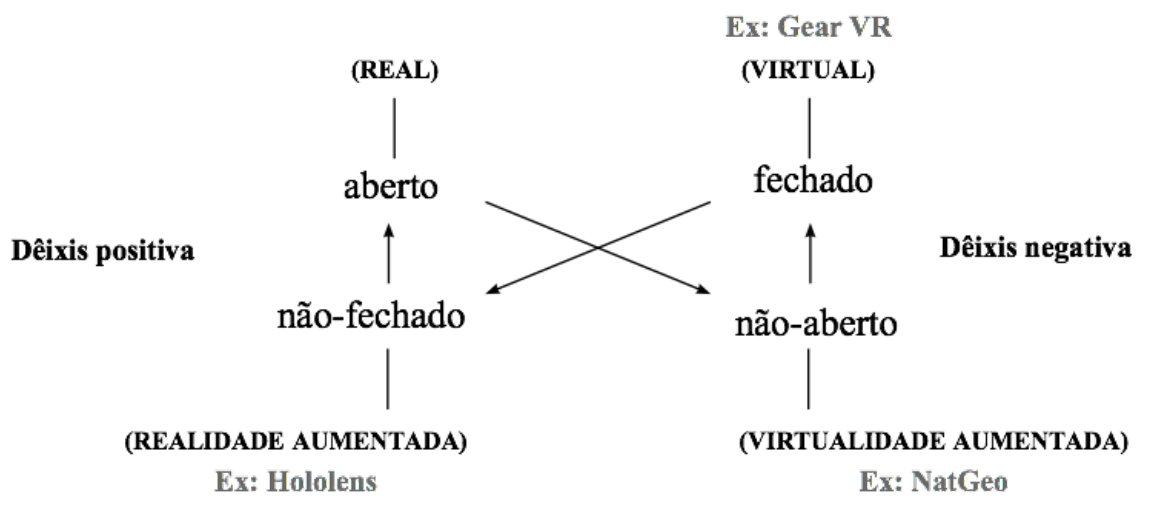

Fig. 5. "Realidade aumentada" e "virtualidade aumentada".

Fonte: Autor. 


\section{Opacidade e transparência: efeitos de sentido}

Em termos produtivos, qualquer posição que se tome - dêixis positiva ou dêixis negativa - terá suas próprias consequências. E estas estão inteiramente ligadas ao terceiro tipo de quadro mencionado por Aumont: o quadro-janela. De acordo com o autor, toda imagem é ao mesmo tempo "ótica e imaginário", "campo visual e campo fantasmático", de modo que a imagem "é feita para que nos percamos nela - sabendo, ou mais raramente, sem o saber" (2004, p. 115).

O sentido de "perder-se numa imagem" parece estar associado nesse caso à ideia de se deixar levar pelo que os olhos veem, deixar-se encantar, como se a vista pudesse presenciar um sentido mágico e impossível de ser realizado com base na situação imediata do sujeito e das leis de seu entorno - ontológico ou midiático, conforme a situação. E o que dizer quanto ao "grau de consciência" acerca de si próprio ou de se perder numa dada imagem? Que relação isso pode ter com as quatro noções apresentadas no decorrer deste texto (aberto, fechado, não-aberto, não-fechado)?

Na esfera da representação, quanto mais evidente for a presença do dispositivo - neste caso específico, o quadro-moldura e o quadro-limite - maior será a consciência do sujeito a respeito das imagens a ele reveladas e, consequentemente, maior o seu espírito crítico e distanciamento psíquico. Por outro lado, quanto menor for a presença ou a evidência da aparelhagem utilizada, maior será seu poder de ilusão. A essas noções, dá-se o nome, respectivamente, de opacidade e transparência:

Quando o 'dispositivo' é ocultado, em favor de um ganho maior de ilusionismo, a operação se diz de transparência. Quando o "dispositivo" é revelado ao espectador, possibilitando um ganho de distanciamento e crítica, a operação se diz de opacidade (XAVIER, 2008, p. 6).

Nisso reside, mais ou menos, o estado de "saber" ou "não saber" do sujeito, conforme evocado por Aumont. Se voltarmos ao quadro como um operador de espaços e aos efeitos de sentido que podem ser alcançados a partir da oposição categórica aberto vs. fechado, isto é, do tipo de representação e interação que podem proporcionar, tem-se que na dêixis negativa a presença do dispositivo é mais evidente e, portanto, a consciência do sujeito acerca dos meios empregados para a construção e exibição da imagem também é maior, resultando em maior afastamento psicológico e posicionamento crítico. Isso explica por que, ainda que o sujeito venha a estar imerso num determinado ambiente artificial, tenderá a atribuir às imagens que lhe são apresentadas um sentido de ficção.

Já na dêixis positiva, a presença do dispositivo é menos evidente, fazendo diminuir a consciência do sujeito acerca dos meios empregados para a construção e exibição da imagem, resultando em menor distanciamento psicológico e posicionamento crítico. É por esse motivo que as imagens do mundo natural tendem a ser tomadas como verdade 
pelo sujeito que as observa, ainda que sejam por vezes apreendidas por perspectivas muito limitadas ou mesmo equivocadas do olhar - revelando o poder ilusório desse tipo de imagem, isto é, desse tipo de construção da imagem.

É importante ressaltar que esses qualificativos para as dêixis - positiva e negativa não comportam um investimento axiológico: estes só irão aparecer em cada caso depois da projeção, no quadrado semiótico, da categoria tímica euforia/disforia (GREIMAS; COURTÉS, 1983, p. 104, verbete Dêixis). Isso significa que, dependendo do contrato proposto, o objeto de valor poderá estar ora sobre os efeitos de sentido de realidade, ora sobre os efeitos de sentido de ficção. E caberá ao sujeito da enunciação articular os elementos formais de que dispõe - tais como os que giram em torno da espacialidade -, a fim de obter o efeito de sentido desejado em busca da adesão do enunciatário.

\section{Considerações finais}

Se a expressão cunhada por Lanier tinha por objetivo significar experiências articuladas sobre modos de existência contrários, a representação visual do quadrado semiótico ajuda-nos a perceber que os esforços a serem realizados nesse intuito devem ser dirigidos aos sub-contrários. Isso se dá porque eles, à medida que negam um determinado modo de existência e afirmam outro em direção oposta, passam a gozar de uma condição intermediária - que pode "estar um pouco mais para lá" ou "um pouco mais para cá", conforme a dêixis em que se encontram.

Quanto ao viés da espacialidade, o que fizemos foi eleger um dentre outros eixos semânticos possíveis, dada a polissemia que envolve os termos eleitos por Lanier - o real e o virtual. Com isso, vimos como a questão pode ser abordada a partir da noção de quadro ou, mais exatamente, a partir da oposição formal aberto vs. fechado e dos efeitos de sentido de realidade vs. ficção que deles podem ser depreendidos. Portanto, as experiências que buscam articular os dois modos de existência mencionados deverão se posicionar numa ou noutra dêixis conforme o efeito de sentido pretendido: menor ilusionismo na dêixis negativa (não-aberto) e maior ilusionismo na dêixis positiva (não-fechado).

Jaqueline Esther Schiavoni é doutora em Meios e Processos Audiovisuais pela ECA-USP e pesquisadora do Grupo de Estudos Audiovisuais (GEA), da Unesp/Bauru.

jeschiavoni@yahoo.com.br

\section{Referências}

AUMONT, J. O olho interminável: cinema e pintura. São Paulo: Cosac \& Naify, 2004. 
A imagem. $6^{\text {a }}$.ed. Trad. Estela dos Santos Abreu e Cláudio C. Santoro. Campinas: Papirus, 2001.

DELEUZE, G. Différence et répétition. Paris: PUF, 1968.

GREIMAS, A. J.; COURTÉS, J. Dicionário de semiótica. Trad. Alceu Dias Lima et. al. São Paulo: Cultrix, 1983

LÉVY, P. O que é o virtual? Trad. Paulo Neves. São Paulo: Editora 34, 2001.

KIRNER, C.; SISCOUTTO, R. A. Fundamentos de realidade virtual e aumentada. In: KIRNER, C.; SISCOUTTO, R. A. (Orgs.) Realidade virtual e aumentada: conceitos, projeto e aplicações. Porto Alegre: Editora SBC (Sociedade Brasileira de Computação), 2007.

KIRNER, C.; KIRNER, T. G. Evolução e tendências da realidade virtual e da realidade aumentada. In: RIBEIRO, M. W.; ZORZAL, R. (Orgs.) Realidade virtual e aumentada: aplicações e tendências. Uberlândia: Editora SBC (Sociedade Brasileira de Computação), 2011.

PEREIRA, M. D. A expressão da natureza na obra de Paul Cézanne. Rio de Janeiro: Sette Letras, 1998.

QUÉAU, P. Lo virtual: virtudes y vértigos. Barcelona: Paidós, 1995.

ROSSI, J. A internet está errada. Veja, 16 de julho de 2010. Disponível em: http://veja.abril.com.br/ tecnologia/a-internet-esta-errada/. Acesso em: 31 maio 2017.

XAVIER, Ismail. O discurso cinematográfico: a opacidade e a transparência. $4^{a}$ ed. São Paulo: Paz e Terra, 2008.

\section{Referências audiovisuais}

SAMSUNG gear vr commercial \#2. NovaTech SE. YouTube, 24 de janeiro de 2016. 2 min29s. Disponível em: <https://www.youtube.com/watch?v=-zmdN8Z0qEY>. Acesso em: 8 fev. 2018.

HOLOLENS. Holo Lens Studio Demo. Windows 10. Michosoft Hololens. Mehul Acharya. YouTube, 21 de janeiro de 2015. 9min06s. Disponível em: https://www.youtube.com/watch?v=qym11JnFQBM. Acesso em: 8 fev. 2018.

LIVE Augmented reality-national geographic. AvatarSupiddGuy. Youtube. 07/11/2011. 3min. Disponível em: <https://www.youtube.com/watch?v=D0ojxzS1fCw>. Acesso em: 8 fev. 2018.

Artigo recebido em 08/02/2018

e aprovado em 02/06/2018. 